Original Research Article

\title{
Spectrum of neonatal surgical emergency- a study in rural area tertiary care center of western U.P
}

\author{
Gupta U.K ${ }^{1}$, Kumar $S^{2}$, Kunwar $B^{3}$, Yadav Y.S ${ }^{4}$ \\ ${ }^{1}$ Dr. Umesh Kumar Gupta, Assistant Professor, Pediatrics Surgery, ${ }^{2}$ Dr. Shesh Kumar, Assistant Professor, \\ General Surgery, ${ }^{3}$ Dr. Kunwar Bharat, Assistant Professor, Pediatrics Medicine, ${ }^{4}$ Dr. Yogendra Sing Yadav, \\ Assistant Professor, Pediatrics Medicine, all authors are affiliated with U.P.U.M.S, Saifai, Etawah, U.P, India.
}

Address for Correspondence: Dr. Shesh Kumar, Department of General Surgery, U.P.U.M.S. Saifai, Etawah, U.P, India. E-mail: dukg9999@gmail.com

\begin{abstract}
Introduction: Neonatal Intestinal obstruction is commonest surgical cause in emergency, in which rapid intervention is required to prevent undesirable side effect of obstruction that includes death. This study provides spectrum of intestinal obstruction in neonates and sex prediction. Material and Method: This is prospective study done in neonates with feature of intestinal obstruction attending emergency and outdoor of Pediatrics Surgery, Pediatrics Medicine and General Surgery of U.P.U.M.S , Saifai, Etawah during period of January 2016-December 2016. Result: During the study period of one year total 44 patents admitted to our side with features of neonatal obstruction in which male female ratio was 3.8:1. Out of these 44 neonates Anorectal malformation was found in 61.36\% neonates, Hirschsprung's Disease in 9.09\%, Duodenal obstruction in 6.81\%, Hernia of umbilical cord in 4.54\%, Atresia in 4.54, Congenital peritoneal band in $2.27 \%$, Meconium obstruction in $2.27 \%$, Malrotation in 2.27\%, Meckel's band obstruction in 2.27\%, Ileal knotting in 2.27\%, Idiopathic hypertrophic pyloric stenosis (IHPS) in $2.27 \%$. Conclusion: Early identification and surgical management in neonatal intestinal obstruction decrease morbidity and motilities in neonates. Reason of male sex predominance is not known, it may be due to less attention towards female child by social custom in our society.
\end{abstract}

Keywords: Neonates, Surgical emergency, Neonatal intestinal obstruction

\section{Introduction}

Passage of first meconium within 24 to 48 hour is indication of wellbeing of newborns. First meconium is passed by all full term healthy neonates within 24 hours of birth [1]. Unable to pass meconium within 48 hour after birth raises the suspicion of intestinal obstruction. The incidence of neonatal intestinal obstruction is approximately 1 in $2000[2]$.

Studies shows that stool frequency during first week of life is more than three to four per day and it gradually decrease to two stools per day at four month and this frequency further decrease to one stool per day for four years of age with gradual increase in stool size and weight $[3,4]$. Newborn baby in initial few day of postnatal life does not

Manuscript received: $30^{\text {th }}$ May 2017

Reviewed: $10^{\text {th }}$ June 2017

Author Corrected: $20^{\text {th }}$ June 2017

Accepted for Publication: $28^{\text {th }}$ June 2017 appear sick until secondary change due to repeated vomiting or vascular changes developed in involved dilated bowel loop. Sepsis, intrapartum heavy sedation or analgesia i.e. morphine, birth asphyxia, hypothyroidism, cystic fibrosis of pancreas can produce intractable vomiting or constipation mimicking anatomical obstruction and causing diagnostic dilemma.

Neonatal intestinal obstruction has various etiologies depending upon age. These etiologies may have regional variations. Children with intestinal obstruction can be divided as neonatal intestinal obstruction and non-neonatal intestinal obstruction [5]. Neonatal intestinal obstruction can be divided in high intestinal obstruction and low intestinal obstruction. The differential diagnosis of lower intestinal obstruction are Hirschsprung's Disease and it's allied like hypo-ganglionosis, 
intestinal neuronal dysplasia, anorectal malformation, meconium plug syndrome, small left colon and differential diagnosis of upper intestinal obstruction are Duodenal atresia and Annular pancreas, Malrotation with midgut volvulus, Jejuno-ileal atresia [6].

In high obstruction vomiting is first sign and abdominal distension is last sign and distension is minimal or may be limited to upper part of abdomen where as in low intestinal obstruction abdominal distension is early feature and involves whole abdomen and vomiting is last sign.

\section{Material and Method}

This is prospective study done at U.P.U.M.S. Saifai, Etawah, U.P. from January 2016 December 2016. During this period all the neonates with feature of intestinal obstruction i.e. bilious vomiting, abdominal distension, delayed passage of meconium or absolute constipation, attending emergency and outdoor of Pediatrics Surgery, Pediatrics Medicine, General Surgery U.P.U.M.S., Saifai, Etawah and operated here were included in this study. All neonates resuscitated and properly examined and required investigation like blood and serum examination, X-ray, Ultra sonogram, contrast enema done. After complete evaluation and stabilization neonates were operated i.e. in anorectal malformation on basis of distal bowel shadow with relation of sacrum, colostomy or primary posterior sagittal anorecto-plasty done, in suspected Hirschsprung"s disease levelling colostomy done, in malrotation Ladd's procedure done, in hernia of umbilical cord and atresia exploratory laparotomy and resection anastomosis, in congenital band excision of band done, in meconium obstruction Bisop koop operation, in Idiopathic hypertrophic pyloric stenosis Ramstedt's operation was performed.

Post operatively proper care and supportive treatment was given. On improvement in neonatal physical condition neonates were allowed oral feed and discharged accordingly.

Inclusion criteria: All the neonates admitted with feature of mechanical and surgical cause of functional obstruction and operated in U.P.U.M.S. Saifai, Etawah.

\section{Exclusion criteria}

- Trauma patients

- Free gas under diaphragm

- Neonates presented with sepsis

- Post diarrheal distension

- Obstruction due to any tumor mass

- Neonates with mother history of sedation, eclampsia

- Patient's guardian not willing for operative procedure

\section{Result}

In one year of study period total 44 neonates admitted and operated for features of neonatal intestinal obstruction. In this study the male female ratio noted was 3.8:1. Out of these neonates maximum number of

Table-1: Etiology - Demographic profile.

\begin{tabular}{|c|c|c|c|}
\hline S. No & Etiology & Male & Female \\
\hline 1 & Anorectal malformation & 19 & 8 \\
\hline 2 & Hirschsprung's Disease & 4 & - \\
\hline 3 & Duodenal obstruction & 2 & 1 \\
\hline 4 & Hernia of umbilical cord & 2 & - \\
\hline 5 & Congenital peritoneal band & 1 & - \\
\hline 6 & Meckel's band obstruction & 1 & - \\
\hline 7 & Meconium obstruction & 1 & - \\
\hline 8 & Malrotation & 1 & - \\
\hline 9 & Atresia- & 1 & - \\
& - Jejuno-ileal atresia & 1 & - \\
\hline 10 & - Sigmoid atresia & 1 & \\
\hline 11 & Ileal knotting & & \\
\hline
\end{tabular}


patient's were of Anorectal malformation (61.36\%) whereas the other causes like Hirschsprung's Disease was found in $9.09 \%$, Duodenal obstruction was found in $6.81 \%$, Hernia of umbilical cord was found in $4.54 \%$, atresia was found in 4.54 and Congenital band, Meckel's band obstruction, Meconium obstruction, Malrotation, Ileal knotting and IHPS each was found in $2.27 \%$. During this period three neonates expired. one patient each of Malrotation and Jejuno-ileal atresia expired due to sepsis and another one expired due to cardiac anomalies with Anorectal malformation.

Table-2: Etiologies of neonatal intestinal obstruction

\begin{tabular}{|c|c|c|c|}
\hline S. No & Etiology & No of patient & Percentage \\
\hline 1 & Anorectal malformation & 27 & $61.36 \%$ \\
\hline 2 & Hirschsprung's Disease & 4 & $9.09 \%$ \\
\hline 3 & Duodenal obstruction & 1 & $6.81 \%$ \\
\hline 4 & Hernia of umblical cord & 1 & $4.54 \%$ \\
\hline & $-\quad$ Meckel's diverticula & 1 & $4.54 \%$ \\
\hline 5 & $-\quad$ Ileal atresia & 1 & $2.27 \%$ \\
\hline 6 & Atresia & 1 & $2.27 \%$ \\
\hline 7 & $-\quad$ Sigmoid atresia & 1 & $2.27 \%$ \\
\hline 8 & Congenital peritoneal band & 1 & $2.27 \%$ \\
\hline 9 & Meckel's band obstruction & 1 & $2.27 \%$ \\
\hline 10 & Meconium obstruction & 1 & $2.27 \%$ \\
\hline 11 & Malrotation & 1 & \\
\hline
\end{tabular}

Table 3- Distribution of neonates according surgical procedure.

\begin{tabular}{|c|c|c|c|c|}
\hline S. No & Etiology & Procedure & $\begin{array}{c}\text { Number } \\
\text { of patients }\end{array}$ & Percent \\
\hline 1 & Anorectal malformation & Proximal sigmoid colostomy & 21 & $47.27 \%$ \\
& & Minimal PSARP & 2 & $4.54 \%$ \\
& & Rt. trans. colostomy & 2 & $4.54 \%$ \\
\hline 2 & Hirschsprung's Disease & ASARP with sigmoid colostomy & 2 & $4.54 \%$ \\
\hline 3 & Duodenal obstruction & Duodeno-duodenostomy & 4 & $9.09 \%$ \\
\hline 4 & Congenital peritoneal band & Band excision & 1 & $6.81 \%$ \\
\hline 5 & Meckel's band obstruction & Band excision & 1 & $2.27 \%$ \\
\hline 6 & Hernia of umbilical cord & Laparotomy followed by resection & 2 & $4.54 \%$ \\
\hline 7 & Meconium obstruction & anastomosis & 1 & $2.27 \%$ \\
\hline 8 & Malrotation & Bishop koop operation & 1 & $2.27 \%$ \\
\hline 9 & Atresia- Jejuno-ileal & Ladd's procedure & 1 & $2.27 \%$ \\
\hline 10 & Sigmoid & Resection anastomosis & 1 & $2.27 \%$ \\
\hline 11 & IHPS & & 1 & $2.27 \%$ \\
\hline
\end{tabular}




\section{Discussion}

In new born abdomen is protuberant so abdominal distension of early stage of obstruction is difficult to differentiate with normal protuberant abdomen and in case of duodenal obstruction in which minimal or no distention can present. Bilious vomiting is reliable indicator of high intestinal obstruction. Colour pattern of bile can differentiate functional obstruction from anatomical obstruction. Bile is golden yellow or light green in functional obstruction while dark green in mechanical or anatomical obstruction. Dann (1936) in his study, found that bile pigment rarely present in patient's of functional obstruction. Pigment found in functional obstruction is carotenoid type which is present in large amounts in colostrums [7].

Intractable non bilious vomiting, sign of dehydration with palpable olive is suggestive of idiopathic hypertrophic intestinal obstruction. Absolute constipation is hallmark of obstruction but normal passage of few episode of meconium can not rule out that patient have no obstruction. Meconium starts to collect in second half of intrauterine life [8]. Meconium collected beyond the obstruction site can pass normally in neonates with intestinal obstruction. Examination of inguino-scrotal area and anal area can identify obstructed hernia, ano-rectal malformation i.e. perineal fistula, anal atresia, rectal atresia, classical Hirschsprung's Disease. In case of classical Hirschsprungs's disease on anal dilation passage of gush of air and meconium or stool is suggestive of this illness. Antenatal Ultrasonography in higher obstruction i.e. duodenal obstruction atresia, web, annular pancreas \& malrotation show polyhydramnios in mother. Polyhydramnios is defined as deepest vertical pool on USG is more than $8 \mathrm{~cm}$ [9]. However absence of polyhydramnios does not exclude obstruction.

USG in idiopathic hypertrophic pyloric stenosis shows pyloric muscle thickness more than $4 \mathrm{~mm}$ and length more than $14 \mathrm{~mm}$ is suggestive of disease [10,11]. In malrotation abnormal relationship of superior mesenteric artery and vein by help of colour Doppler is suggestive. Superior mesenteric vein left to artery or spiral twisting of vein and artery is highly suggestive of malrotation and further conformation can be done in upper GI contrast study. Plain X ray abdomen is sufficient most of time to diagnose neonatal obstruction, swallowed air by newborns reach in the rectum approximately in 24 hour. Plain X-ray abdomen in neonates cannot differentiate small bowel obstruction from large bowel obstruction [12]. Patients of Jejuno- ileal atresia having dilated bowel loop with multiple air fluid level, in meconium ileus granular appearance at right lower abdomen, in Hirschsprung's Disease dilated bowel loop without air fluid level and paucity or absence of rectal gas shadow, in ARM distal bowel gas shadow in respect of sacrum decides primary definitive procedure or staged procedure [13].

X-ray abdomen supine and erect view show multiple dilated bowel loop in lower type intestinal obstruction as compared to higher bowel obstruction i.e. in Pyloric atresia single gas shadow, Duodenal obstruction double gas shadow, in Jejunal obstruction triple gas shadow may be seen. If plain X-ray clinches the diagnosis along with physical examination, laparotomy should be warranted without delay to prevent complication.

Water soluble Contrast enema can suggest Hirschsprung's Disease and partial intestinal obstruction. In Hirschsprung's disease contrast enema may show spastic segment, transitional segment and dilated segment. With the help of contrast enema recto-sigmoid index can calculate. Normal recto sigmoid index is more than one, value less than one is suggestive of Hirschsprung's disease, Confirmatory diagnosis of Hirschsprung's disease is made after rectal biopsy. In meconium ileus and long segment Hirschsprung's disease unused colon / micro colon can be seen. Barium solution is toxic in patient with intestinal obstruction due to risk of barium peritonitis in case of suspected or impending perforation.

\section{Conclusion}

Intestinal obstruction may become life threatening if undiagnosed or improperly managed can progress to vascular compromise which can cause bowel necrosis, perforation and sepsis leading to death of neonates. So early diagnosis and treatment is required to prevent complication of intestinal obstruction.

Funding: Nil, Conflict of interest: None initiated, Perission from IRB: Yes 


\section{References}

1. Loening-Baucke V, Kimura K. Failure to pass meconium: diagnosing neonatal intestinal obstruction. Am Fam Physician. 1999 Nov 1;60(7): 2043-50.

2. Glasser $\mathbf{J}$ G. Intestinal Obstruction in the Newborn [internet] .2016March17; Available from: http://emedicine.medscape.com/article/2066380overview\#showall

3. Weaver LT, Steiner H. The bowel habit of young children. Arch Dis Child. 1984 Jul;59(7):649-52.

4. Tehuteru S, Firmansyah A, Madiyono B. Bowel habits of exclusively breastfed 0-4 month old babies. Paediatrca Indonesiana. 2004; 44 (4): $138-142$

5. Gangopadhyay A N, Wardhan H. Intestinal obstruction in children in India. Pedi. Surg. Int. 1989;4:84-7.

6. Vinocur DN, Lee EY, Eisenberg RL. Neonatal intestinal obstruction. AJR Am J Roentgenol. 2012 Jan;198(1):W1-10. doi: 10.2214/AJR.11.6931.

7. Nixon H H. Intestinal obstruction in newborns. Arch Dis Child. 1955 February; 30(149): 13-22.
8. Potter E L. Pathology of the Fetus and Infant and child, 2nd ed. Chicago :Mosby;1961.

9. Goldstein R B, Filly R A. Sonographic estimation of amniotic fluid volume- Subjective assessment versus pocket measurements. J Ultrasound Med. 1988;7 (7): 363-369.

10. Hernanz-Schulman M, Neblett WW 3rd, Polk DB, Johnson JE. Hypertrophied pyloric mucosa in patients with hypertrophic pyloric stenosis. Pediatr Radiol. 1998 Nov; 28(11):901

11. Chen EA, Luks FI, Gilchrist BF, Wesselhoeft CW Jr, DeLuca FG. Pyloric stenosis in the age of ultrasonography: fading skills, better patients? J Pediatr Surg. 1996 Jun;31(6):829-30.

12. Baucke V L, Kimura K. Failure to Pass Meconium: Diagnosing Neonatal Intestinal Obstruction. American Academy of Family Physicians.http://www.drplace.com/Failure_to_Pas s_Meconium_Diagno sing_Neon.

13. Pena A, levit M A. Peditric surgery. $7^{\text {th }}$ edition . Philadelphia: Elsevier;2006.

How to cite this article?

Gupta U.K, Kumar S, Kunwar B, Yadav Y.S. Spectrum of neonatal surgical emergency- a study in rural area tertiary care center of western U.P. J PediatrRes.2017;4(06):411-415.doi:10.17511/ijpr.2017.i06.10. 